\title{
Fire-resistance, physical, and mechanical characterization of particleboard containing Oceanic Posidonia waste
}

\author{
J.M. Saval ${ }^{\mathrm{a}}$, R. Lapuente ${ }^{\mathrm{a}}$, V. Navarro ${ }^{\mathrm{b}}$, A.J. Tenza-Abril ${ }^{\mathrm{a}} \bowtie$ \\ a. Universidad de Alicante (Alicante, Spain) \\ b. Centro Técnico del fuego, AIDIMA-AIDICO (Valencia, Spain) \\ \ajt.abril@ua.es
}

\begin{abstract}
In this work, particleboards manufactured with Oceanic Posidonia waste and bonded with cement are investigated. The particleboards are made with 3/1.5/0.5 parts of cement per part of Posidonia waste. The physical properties of bulk density, swelling, surface absorption, and dimensional changes due to relative humidity as well as the mechanical properties of modulus of elasticity, bending strength, surface soundness, perpendicular tensile strength and impact resistance are studied. In terms of the above properties, the best results were obtained for particleboards with high cement content and when the waste "leaves" are treated (crushed) before board fabrication, due to internal changes to the board structure under these conditions. Based on the results of fire tests, the particleboard is non-flammable without any fire-resistant treatment.
\end{abstract}

KEYWORDS: Oceanic Posidonia waste; Particleboard; Cement; Physical and mechanical properties; fire resistance

Citation / Citar como: Saval, J.M.; Lapuente, R.; Navarro, V.; Tenza-Abril, A.J. (2014) Fire-resistance, physical, and mechanical characterization of particleboard containing Oceanic Posidonia waste. Mater. Construcc. 64 [314], e019 http://dx.doi.org/10.3989/mc.2014.01413.

RESUMEN: Caracterización física y mecánica de tableros fabricados con residuo de Posidonia Oceánica y su reacción frente al fuego. En esta investigación se han diseñado y fabricado tableros con residuo de Posidonia Oceánica y cemento. Los tableros se han fabricado con 3/1.5/0.5 partes de cemento por cada parte de Posidonia estudiándose sus propiedades físicas (densidad, hinchazón, absorción superficial, variaciones dimensionales por humedad) y mecánicas (módulo de elasticidad, resistencia a flexión, al arranque de superficie, al arranque de tornillo, a la tracción perpendicular y al choque). Se observa una mejora de los resultados de resistencia mecánica con el incremento de la cantidad de cemento y si la hoja del residuo es previamente tratada ya que proporciona una mejor estructura interna en el tablero. Además, tras los ensayos de reacción al fuego, se observa que el material es no inflamable sin ningún tipo de tratamiento ignifugante.

PALABRAS CLAVE: Residuo de Posidonia Oceánica; Tableros; Cemento; Propiedades físicas y mecánicas; reacción al fuego

Copyright: (C) 2014 CSIC. This is an open-access article distributed under the terms of the Creative Commons Attribution-Non Commercial (by-nc) Spain 3.0 License.

\section{INTRODUCTION}

Oceanic Posidonia (PO) is a Mediterranean marine plant with leaves that are $0.8-1.5 \mathrm{~cm}$ wide and $80-120 \mathrm{~cm}$ long. It grows in undersea meadows at depths ranging from zero to 40 meters. These meadows have a notable ecologic importance since they are a good indicator of water quality. Each year in the fall, these plants lose a significant part of their leaves, between 10 and 20 THa. A part of this loss 
is swept up by tides and accumulates on beaches as berms. Although these accumulations serve to protect beaches from erosion, they are systematically removed from tourist beaches. The removal is performed by heavy machinery that causes a significant loss of beach sand. Additionally, PO disposal is expensive due the high cost of treatment and the great volume of PO waste generated.

With the recent trend toward reduction of the use of raw materials and the problems associated with waste disposal, the recycling of PO waste into a useful material would be beneficial. The construction industry, in particular, could benefit from waste recycling of this resource, because of the large volume of material that it requires. Previous studies have investigated PO waste as a component of cement mortar. The PO waste, incinerated at up to $800{ }^{\circ} \mathrm{C}$, exhibits mineralogical properties similar to DL-80 construction lime, and has cementitious properties (1). The substitution of up to $10 \%$ of cement by PO ash is in compliance with the minimum requirements established for cement (2).

Due to the high demand of wood, many studies have looked at the incorporation of waste in particle board manufacturing. In 2010, wood production for timber and industrial purposes reached $17569000 \mathrm{~m}^{3}$ (3) in Spain.

Cucumber stalks (4), sunflower stalks (5) and eggplant stalks with thermal adhesive (6) may be used to manufacture panels that can be utilized for general purposes and in indoor applications.

In addition to meeting the minimum requirements general purpose and indoor use, particleboards manufactured with tea leaf waste are more resistant to biological agents such as termites and decay-type fungi (7) than normally-manufactured particleboards. Thickness swelling of particleboards manufactured with pine needles is also improved (8-9) when compared to those without pine needles.

Particleboards manufactured using up to $30 \%$ hazelnut husk (10), up to 50\% kiwi stalks (11), or up to $13 \%$ waste grass clippings with eucalyptus (12) also achieve minimum particleboard conditions for general purpose and indoor applications.

The length of the wheat straw and corn stalks used in particleboards affects tensile and compressive strength (13). These particleboards have shown better mechanical properties than those manufactured with other agricultural wastes (14).

In view of the feasibility to using vegetable wastes for the manufacture of particleboards, the aim of this work is to fabricate particleboards with PO waste bonded with cement, study their physical and mechanical behaviour and compare their characteristics with the minimum requirements of various panels in general usage. In addition, we compare the flammability of these particleboards to other panels in usage.

\section{EXPERIMENTAL PROGRAMME}

\subsection{Materials}

The panels were prepared with Portland cement CEM 1/52.5 $\mathrm{R}$ according to the requirements of UNE UN 197-1 (15). The PO residue was collected from beaches in the province of Alicante, Spain. After the leaf residue was collected it was spread on a mesh for a first drying. With the idea of extracting the Rhizomes, spheroids of large size, and any other part of the sample that did not form part of the leaf, a manual screening was performed. This also separated the sand from the leaf particles. The material was then introduced into an oven at $60^{\circ} \mathrm{C}$ to make the drying process easier. This study examines the use of PO in two states, one being in the original state and morphology as collected from the beach (which will be referred to as PO-N from this point on) and the other in which the leaves have been ground by a cutting mill. For this second form the leaf particles were sieved to be sized between UNE $5 \mathrm{~mm}$ and $1.25 \mathrm{~mm}$. We refer to this state as PO-C from this point on. The PO used in this work is shown in Figure 1a.

\subsubsection{Proportions and preparation of the PO cement boards}

Six different mixes were prepared to fabricate and evaluate the properties of the PO panels. Details of the mixes are given in Table 1. In all PO cement boards, the proportion of $\mathrm{PO}$ and water were maintained at the constant ratio of 1:2 (one part PO to two parts of water) to determine the effect of various quantities of cement on the mix. The large amount of water used in the manufacture of the samples was due to the high absorption of the PO. The ratios 3, 1.5 , and 0.5 of cement to PO were used for making the PO cement boards. Higher proportions of cement in the panels caused an undesirable increase of density and lower quantities caused the collapse of the samples.

In order to simplify identification of the mix used in test sample preparation, the abbreviation "PO-N" is used for the test samples made with the natural leaf morphology and "PO-C" for samples made with the ground leaf morphology. The number following the abbreviation, either 30,15 or 05 , indicates the proportion of cement in the mix, either $3,1.5$, or 0.5 , respectively.

The mixes for the specimens were made in two stages in order to improve the workability and to obtain complete mixing of the components. The cement and water were combined in the first phase of the cement batch. In this way, agglomeration during the mixing was avoided and a uniform distribution of the $\mathrm{PO}$ was achieved in the matrix. Afterwards, the PO was added little by little until 
TABLE 1. Proportions of components used in test sample fabrication

\begin{tabular}{lcccc}
\hline Mix n $^{\circ}$ & Specimen size $(\mathbf{m m})$ & Cement $(\mathbf{g})$ & Water $(\mathbf{g})$ & PO $(\mathbf{g})$ \\
\hline PO-C-05 & $300 \times 400 \times 20$ & 360 & 1440 & 720 \\
PO-C-05 & $300 \times 400 \times 10$ & 180 & 720 & 360 \\
PO-C-15 & $300 \times 400 \times 20$ & 1080 & 1440 & 720 \\
PO-C-15 & $300 \times 400 \times 10$ & 540 & 720 & 360 \\
PO-C-30 & $300 \times 400 \times 20$ & 2160 & 1440 & 720 \\
PO-C-30 & $300 \times 400 \times 10$ & 1080 & 720 & 360 \\
PO-N-05 & $300 \times 400 \times 20$ & 360 & 1440 & 720 \\
PO-N-05 & $300 \times 400 \times 10$ & 180 & 720 & 360 \\
PO-N-15 & $300 \times 400 \times 20$ & 1080 & 1440 & 720 \\
PO-N-15 & $300 \times 400 \times 10$ & 540 & 720 & 360 \\
PO-N-30 & $300 \times 400 \times 20$ & 2160 & 1440 & 720 \\
PO-N-30 & $300 \times 400 \times 10$ & 1080 & 720 & 360 \\
\hline
\end{tabular}

the mix became uniform and homogeneous. At this point, it was poured into the moulds. Table 1 indicates the dimensions of the fabricated samples.

In order to accomplish the required dimensions for testing, the cement boards were manufactured by applying a load of 18 tons over a 24 hour period. This period was satisfactory to avoid deformation of the samples due to the decompression of the particleboard. At the end of this period, the PO cement boards were removed from their moulds (see Figure 1b) and no damage was observed. After removal from the moulds the cement boards were then set on wood sheets and remained there under controlled laboratory conditions (Relative Humidity $=65 \%$, temperature $=20{ }^{\circ} \mathrm{C}$ ) for a 24 hour period, after which they were turned upside down every two days so that the part of the sample contacting the wood wouldn't accumulate moisture. This procedure was continued up until the date of testing (90 days), in order to ensure proper setting and hardening and to reach a constant humidity in the particleboard.

After 28 days had passed, the next step was to cut the cement boards to obtain specimens of smaller dimensions as required by testing regulations.

\subsection{Methods}

\subsubsection{Physical Properties}

The tests to determine the physical properties of the particleboards were performed according to Spanish UNE norms as shown in Table 2.

To study the porous structure of the particleboards, the Mercury Intrusion Porosimetry technique was employed using an Autopore IV 9500 Micrometrics porosimeter. This device can measure pressures up to $228 \mathrm{MPa}$, which permits pore analysis in the range of $0.005-180 \mu \mathrm{m}$. Test samples were obtained by extracting an interior fragment from one of the specimens described in the previous section, and analyzing the distribution of pores by size. The pore size distribution study was carried out assuming the following intervals: $<100 \mathrm{~nm}, 100 \mathrm{~nm}$ $-1 \mu \mathrm{m}, 1-10 \mu \mathrm{m}, 10 \mu \mathrm{m}-0.1 \mathrm{~mm}$ and $>0.1 \mathrm{~mm}$.

\subsubsection{Mechanical Properties}

The tests used to determine the mechanical properties of the particleboards were carried out according to the norms shown in Table 3. Figure 2 shows

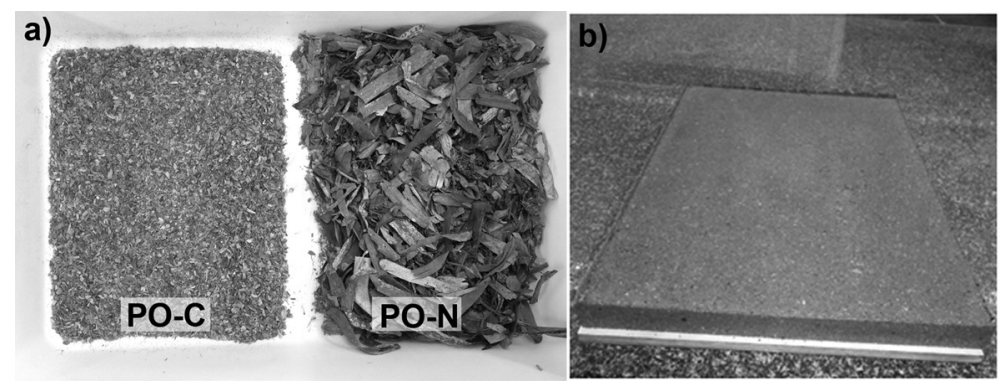

FIgURE 1. a) PO-C and PO-N samples used to manufacture the particleboards b) the sample, after removal from the mould. 
TABLE 2. Test to determine the physical properties of the test samples

\begin{tabular}{lc}
\hline Bulk density & UNE EN 323 \\
Swelling in thickness after immersion in water & UNE EN 317 \\
Dimensional changes associated with changes in relative humidity & UNE EN 318 \\
Surface absorption & UNE EN 382-1 \\
\hline
\end{tabular}

TABle 3. Test to determine the mechanical properties of the test samples

\begin{tabular}{lc}
\hline Bending Modulus of elasticity and bending strength & UNE EN 310 \\
Surface soundness & UNE EN 311 \\
Resistance to axial withdrawal of screws & UNE EN 320 \\
Tensile strength perpendicular to the plane of the board & UNE EN 319 \\
Hard body impact resistance & UNE EN 1128
\end{tabular}

images of some of the mechanical tests that were performed on the PO particleboards.

The bending resistance and the bending modulus of elasticity were obtained by averaging the test results from three samples taken from three different particleboards. Figure 2(a) shows the device used for measuring the force used to bending the particleboard. In order to calculate the bending strength according to UNE EN 310, the bending moment corresponding to the maximum load was determined from equation [1]. Knowing the change in load over the linear portion of the load deformation curve given by equation [2], the bending modulus of elasticity $\left(E_{m}\right)$ was determined.

$$
f_{m}=\frac{3 \cdot F_{\text {máx }} \cdot l_{1}}{2 \cdot b \cdot t^{2}}
$$

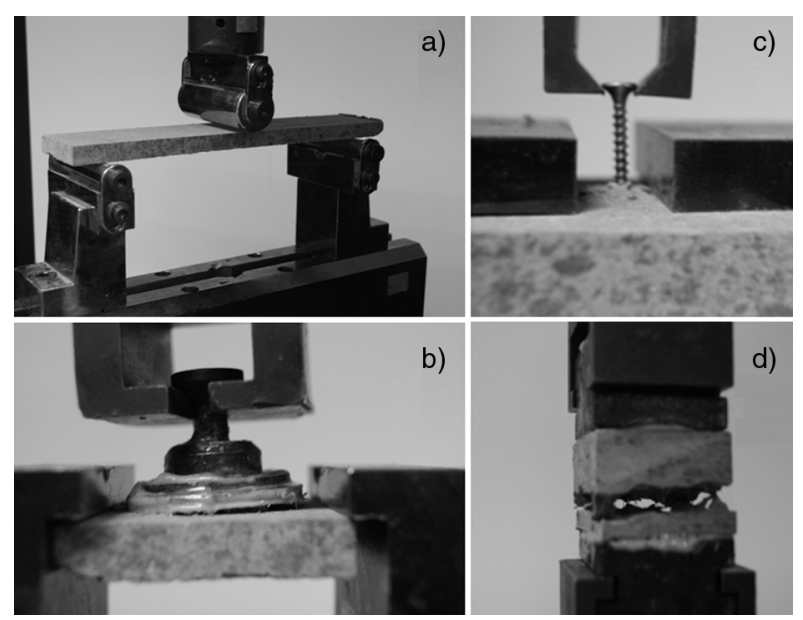

FIGURE 2. a) Bending strength and bending modulus of elasticity tests, b) Surface soundness test, c) Resistance to axial withdrawal of screws test, and d) Tensile strength perpendicular to the plane of the board test.

$$
E_{m}=\frac{\left[l_{1}^{3} \cdot\left(F_{2}-F_{1}\right)\right]}{\left[4 \cdot b \cdot t^{3} \cdot\left(a_{2}-a_{1}\right)\right]}
$$

where $F_{\text {máx }}$ is the rotational bending load of the sample, $l_{1}$ is the length between the supports $(200 \mathrm{~mm}), b$ is the sample width $(50 \mathrm{~mm}), t$ is the thickness $(10 \mathrm{~mm}),\left(F_{2}-F_{1}\right)$ is the change in load over the linear portion of the graph and $\left(a_{2}-a_{1}\right)$ is the change in deformation at the longitudinal midpoint of the sample.

Test samples were taken from three different particleboards. The surface soundness (SS) test for boards was conducted according to UNE EN 311. Square samples measuring $50 \mathrm{~mm}$ along each side and $10 \mathrm{~mm}$ in thickness were used in these tests. Figure 2(b) shows the instrument used in the surface soundness test at the moment the mushroom-shaped pad is pulled free from the particleboard. The surface soundness was obtained from equation [3].

$$
S S=\frac{F}{A}
$$

Where $F$ is the maximum force needed to pull the steel mushroom-shaped pad off the sample and $A$ is the disc-shaped area that circumscribes the slot.

The force needed to pull out a standardized screw was also measured, where the force was aligned with the axis of the screw as required by the norms of UNE EN 320. Figure 2(c) shows the apparatus used to test one of the PO particleboards. The force required to pull out the screw was determined from the mean of measurements taken from three samples.

The tensile strength perpendicular to the plane of the board $\left(f_{t}^{\perp}\right)$ of the PO test samples was determined by applying the force uniformly until a rupture in the 
test sample, that is glued to the block, occurred. The test was repeated three times and the force was computed from the mean of the three results. Figure 2(d) shows one of the samples at the moment of rupture in one of the tests. The tensile strength was calculated according to the equation [4].

$$
f_{t}^{\perp}=\frac{F_{\text {máx }}}{a \times b}
$$

Where $F_{\text {máx }}$ is the load that produces the rupture and $a$ and $b$ are the dimensions of the test sample in contact with the block.

Finally, we determined the hard body impact resistance $(I R)$ according to rules given in UNE EN 1128. Again the hard body impact resistance is the average computed from three tests, each taken from a sample from a different PO particleboard. The calculation of the hard body resistance (IR) was computed with the equation [5].

$$
I R=\frac{H-25}{t}
$$

Where $H$ is the height of the fall that produced the rupture or fissuring in the test simple and $t$ is the sample thickness.

\subsubsection{Flammability Properties. Reaction to fire.}

Flammability tests are required for all construction products or structural elements. These tests evaluate the propensity of a material to spread a fire, and are designed to indicate whether the material is flammable or not.

The flammability tests for the particleboard samples were executed in accordance with the norms shown in Table 4 . The test samples were initially placed in a controlled environment at $23{ }^{\circ} \mathrm{C}$ with a relative humidity of $50 \%$ and were then brought to a constant mass.

In order to determine the calorific value of the specimens, they were first ground and burned under standardized conditions. This test determines the quantity of heat energy in a material that is available for combustion in the event of a fire. The calorific values are the mean results taken from measurements made on three test samples.

The epiradiator method was used to evaluate the indices of: ignitability (i), flame spread (s), maximum flame height (h) and combustion (c). Three samples were prepared for each particleboard in the same manner as that described in the previous test and these samples were then subjected to constant heat from a radiant heater for twenty minutes. During this time, the combustion of any released gases from the particleboards was observed as well as the spread of this combustion. The time necessary for combustion of the bottom and top faces of the specimen were noted, as well as the time at which the flames self-extinguished. The height of the flames was measured during each 30 second period. Furthermore, other aspects of the fire were noted, such as dripping, smoke emission etc.

In the single flame source test, the specimen is placed in a support in a vertical position (Figure 3 ) in the inside of a standardized chamber equipped with an exhaust hood. A mobile burner mounted on a horizontal plane is set so that the flame is at a $45^{\circ}$ angle with the vertical axis. A stable $20 \mathrm{~mm}$ long flame is applied at a $16 \mathrm{~mm}$ distance from the specimen for 15-30 seconds, during which the quantity of falling particles and flaming drops are observed at the bottom of the chamber. The tests were carried out on two test samples for each type of particleboard.

The out-dated UNE 23727 (16) established the classes M0, M1, M2, M3 and M4 for materials based on their combustibility and flammability. This classification indicates the propensity of the material to assist the development of a fire, as may be observed in Table 5.

A new Spanish classification has been established (royal decree R. D. 312-2005) which is consistent with the European norm UNE EN 13501 (17). However, the relationship between classifications established in both norms applies to non-regulated materials (Table 6).

The UNE EN 13501-1 norm requires that the tests be carried out under conditions consistent with the use of the product (coating for wall, ceiling, insulation, floor, etc.), including testing using typical sizing of the product. We decided to test the material according with the out-dated UNE 23727, based on available materials.

\section{RESULTS AND DISCUSSION}

\subsection{Physical Properties}

The physical properties of the particleboards are shown in Table 7 . Each result is the mean taken from three test sample measurements plus or minus

TABLE 4. Flammability tests performed on the particleboards

\begin{tabular}{ll}
\hline Determination of the gross heat of combustion (calorific value) & UNE EN ISO 1716 \\
Epiradiator test used for rigid materials & UNE 23721 \\
Ignitability. Single-flame source test & UNE EN ISO 11925-2
\end{tabular}




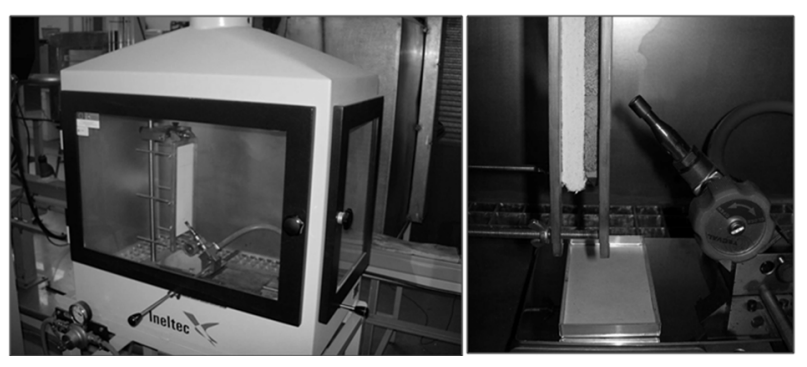

FIGURE 3. The left figure shows the apparatus used to determine sample flammability using the single flame test. The right figure shows the burner utilized in the test along with the vertically-placed test sample.

a single standard deviation. The measured mean densities increase in proportion to the quantity of cement used in fabrication. The densities were similar for the PO-C and PO-N but the densities of the particleboards fabricated with modified PO (PO-C) were a little higher than those using PO in its natural state, principally due to the fact that the modified PO leaves were smaller, allow greater PO-C compaction.

Table 7 gives the mean percent increase in particleboard thickness due to swelling after immersion in water. It is inversely related to the percentage of cement in the particleboard, because there is less binding material as the percentage of cement decreases. When panels absorb water they increase in volume. The dimensional stability increases when the cement content is increased. This may be explained on the basis that cement has low solubility in water, and therefore, may cover the PO particles reducing their

TABLE 5. Classification according to UNE 23727

\begin{tabular}{lcl}
\hline Classification & Combustible & Flammability \\
\hline M0 & NO & NO \\
M1 & YES & NO \\
M2 & YES & YES (moderate) \\
M3 & YES & YES (middle) \\
M4 & YES & YES (high) \\
\hline
\end{tabular}

absorption of water and preventing their expansion (18). The particleboards with PO-C had a greater percent increase in swelling than those made with PO-N. These results confirm that the leaf geometry has an important effect on the dimensional stability of the particleboards. The incorporation of particles of long length tends to improve dimensional stability (19). The specific surface of the PO-N is lower than PO-C because the leaves are both longer and larger. PO-C panels have a greater cement content per surface unit area. Additionally according to some authors (20), increasing the density of the particleboard material results in a decrease in swelling. Comparing the results with wood-based panels, it may be seen that swelling in PO panels is lower than the maximum values required by norm in particleboards (21), medium density fibreboard (MDF) (22), and oriented strand boards (23).

In order to determine the dimensional variations of the test samples to changes in humidity, the samples were exposed to three separate environments composed of 30\%,65\% and $85 \%$ relative humidity, respectively. Pans with solutions of glycerine and water were used to obtain the required relative humidities. It can be seen from Table 5 that humidity affects the PO-N particleboards less than the PO-C boards. Once again, the PO-C-05 boards exhibited the greatest dimensional variation, especially in high-humidity environments. Although one would expect a decrease in dimensional variation with increasing board density, a clear relationship was not identifiable from the data.

In order to determine the superficial absorption of the particleboards, a drop of toluene was allowed to roll down a test sample that was inclined at $60^{\circ}$ with respect to the horizontal plane. The length of the coloured stain produced by the toluene was then measured, with a longer stain corresponding to a lesser surface absorption coefficient. The results for the surface absorption test show that increasing the percentage of cement in the particleboards decreases the measured surface absorption. Furthermore, the PO-C particleboards have a lower surface absorption than those made with PO-N. This is due to the fact that the PO-C particleboard structure is more

TABLE 6. Relationship between UNE 23727 and UNE EN 13501-1

\begin{tabular}{lccc}
\hline & \multicolumn{3}{c}{ Classification according to UNE EN 13501 norm } \\
\cline { 2 - 3 } $\begin{array}{l}\text { Classification according } \\
\text { to UNE 23727 }\end{array}$ & $\begin{array}{c}\text { Coatings for walls, ceilings, thermal insulation, acoustic and ducts } \\
\text { Coatings for walls, ceilings, thermal insulation } \\
\text { (nonlinear) and acoustic ducts }\end{array}$ & $\begin{array}{c}\text { Linear products for thermal } \\
\text { insulation of pipes }\end{array}$ & Floor coatings \\
\hline M0 & $\mathrm{A} 1 / / \mathrm{A} 2-\mathrm{s} 1, \mathrm{~d} 0$ & $\mathrm{~A}_{\mathrm{L}} / / \mathrm{A} 2_{\mathrm{L}}-\mathrm{s} 1, \mathrm{~d} 0$ & $\mathrm{~A} 1_{\mathrm{FL}} / / \mathrm{A} 2 \mathrm{FL}_{\mathrm{s}} \mathrm{s} 1$ \\
M1 & $\mathrm{B}-\mathrm{s} 3, \mathrm{~d} 0$ & $\mathrm{~B}_{\mathrm{L}}-\mathrm{s} 3, \mathrm{~d} 0$ & $\mathrm{~A} 2 \mathrm{FL}_{\mathrm{FL}}-\mathrm{s} 2$ \\
M2 & $\mathrm{C}-\mathrm{s} 3, \mathrm{~d} 0$ & $\mathrm{C}_{\mathrm{L}}-\mathrm{s} 3, \mathrm{~d} 0$ & $\mathrm{~B}_{\mathrm{FL}}-\mathrm{s} 2$ \\
M3 & $\mathrm{D}-\mathrm{s} 3, \mathrm{~d} 0$ & $\mathrm{D}_{\mathrm{L}}-\mathrm{s} 3, \mathrm{~d} 0$ & $\mathrm{C}_{\mathrm{FL}}-\mathrm{s} 2$ \\
\hline
\end{tabular}


TABLE 7. Results obtained for physical property tests. One standard deviation is included

\begin{tabular}{|c|c|c|c|c|c|c|c|c|c|}
\hline \multirow[b]{3}{*}{ Specimen } & \multirow{3}{*}{$\begin{array}{c}\text { Bulk density } \\
\left(\mathrm{kg} / \mathrm{m}^{3}\right)\end{array}$} & \multirow{3}{*}{$\begin{array}{l}\text { Swelling thickness } \\
\text { after immersion in } \\
\text { water } \\
G_{t}(\%)\end{array}$} & \multicolumn{6}{|c|}{ Dimensional changes associated with changes in relative humidity } & \multirow{3}{*}{$\begin{array}{c}\begin{array}{c}\text { Surface } \\
\text { absorption }\end{array} \\
\text { L (mm) }\end{array}$} \\
\hline & & & \multicolumn{2}{|c|}{$30 \%$} & \multicolumn{2}{|c|}{$65 \%$} & \multicolumn{2}{|c|}{$85 \%$} & \\
\hline & & & e (mm) & $\mathrm{l}(\mathrm{mm})$ & e $(\mathrm{mm})$ & $\mathbf{l}(\mathrm{mm})$ & e (mm) & $1(\mathrm{~mm})$ & \\
\hline PO-C-05 & $448.7 \pm 8$ & $9.3 \pm 1.1$ & -0.3 & -0.3 & -0.2 & 0.1 & 1.0 & 0.8 & 39 \\
\hline PO-C-15 & $944.2 \pm 12.5$ & $2.6 \pm 0.4$ & -0.3 & -0.2 & 0.0 & 0.0 & -0.1 & 0.1 & 136 \\
\hline PO-C-30 & $1411.3 \pm 25.7$ & $1.1 \pm 0.6$ & -0.2 & -0.1 & 0.0 & 0.0 & 0.0 & 2.0 & 255 \\
\hline PO-N-05 & $488.9 \pm 3.7$ & $5.2 \pm 0.8$ & 0.0 & -0.1 & 0.0 & 0.1 & -0.3 & 0.2 & 28 \\
\hline PO-N-15 & $885.5 \pm 56.1$ & $3.1 \pm 0.3$ & 0.1 & -0.1 & -0.1 & 0.0 & 0.3 & 0.1 & 107 \\
\hline PO-N-30 & $1385.3 \pm 54.6$ & $2.3 \pm 0.3$ & 0.0 & -0.1 & 0.0 & 0.1 & -0.3 & 0.2 & 207 \\
\hline Particleboard & - & $13-14^{*}$ & - & - & - & - & - & - & $50-90$ \\
\hline MDF & - & $10-13^{* *}$ & - & - & - & - & - & - & $65-110$ \\
\hline OSB & - & $25^{* * *}$ & - & - & - & - & - & - & $60-130$ \\
\hline
\end{tabular}

Minimum requirements for non-structural particleboards in indoor conditions. The given values are the minimum for 20 mm thickness particleboards.

${ }^{*}$ Particleboards (UNE EN 312), for outdoor conditions.

${ }^{* *}$ Medium-density fibreboard (UNE EN 622).

****iented Strand Boards (UNE EN 300).

compact than the PO-N structure. A practical consequence of the lower surface absorption associated with PO-C boards are the savings in reduced usage of lacquers and paints. The superficial absorption is not included in the norms of the particleboards but is helpful in evaluating the cost of painting or lacquering of the panels. The values shown in the Table 7 are typical in conventional panels.

\subsection{Mechanical Behaviour}

The mean bending strength, mean modulus of elasticity, and bending modulus of elasticity for PO-C and PO-N particleboards are shown in the bar graph in Figure 4. Both bending strength and the modulus of elasticity increase in proportion to the amount of cement in the particleboard.

No significant variations in these results have been obtained from the different PO-C and PO-N particleboards. For the bending strength, the average values increase considerably with the amount of cement ranging from PO-05 to PO-15 in samples. However, only a slight increase was observed between the PO-15 to PO-30 samples. In comparison with the minimum required values for particleboards, MDF (lightweight L-MDF and the panels used in rigid underlay's MDF-RWH) and OSB, it may be observed that the PO-N and PO-C panels do not fulfill the minimum requirements established for particle board panels.

Likewise, the values of the bending modulus increase considerably from the PO-05 to PO-15 panels. A slight increase is observed from PO-15 to PO-30, excluding the PO-C-30 sample whose average value was $1930 \mathrm{MPa}$, however, a significant variability in results for this parameter were probably due to the manual manufacture of the panels. Comparing those results with the minimum requirements of commercial panels, PO-15 and PO-30 exceed the bending modulus of elasticity of the OSB panels.

Figure 5 is a bar graph that shows the average results of the surface soundness $(S S)$ test for each of the PO particleboard configurations studied. As may be observed, the surface soundness increases with cement content for both of PO board types, however, the increase was more marked in the case of the PO-C particleboards. The results indicate that the PO-C-30 particleboard had a higher SS than the rest of the particleboard configurations, reaching a maximum of 0.4 MPa. Increasing surface soundness in particleboards made of a more compact and dense material is to be expected.

Figure 6 illustrates the mean force (aligned with the screw axis) required to withdraw a screw from each of the particleboard configurations as measured in the test described in section 2.2.2. The mean withdrawal force increases with increasing cement content in the particleboards. As shown by the results in the Figure 6, the PO boards with minimal amounts on cement required only a very small amount of force for screw withdrawal. The PO-N-15 y PO-N30 particleboards showed about a $20 \%$ increase in withdrawal force while the withdrawal force for the PO-C-15 y PO-C-30 particleboards almost doubled with increasing cement content. This is due to the fact that the more compact structure of the PO-C particleboard allows for more contact area between 

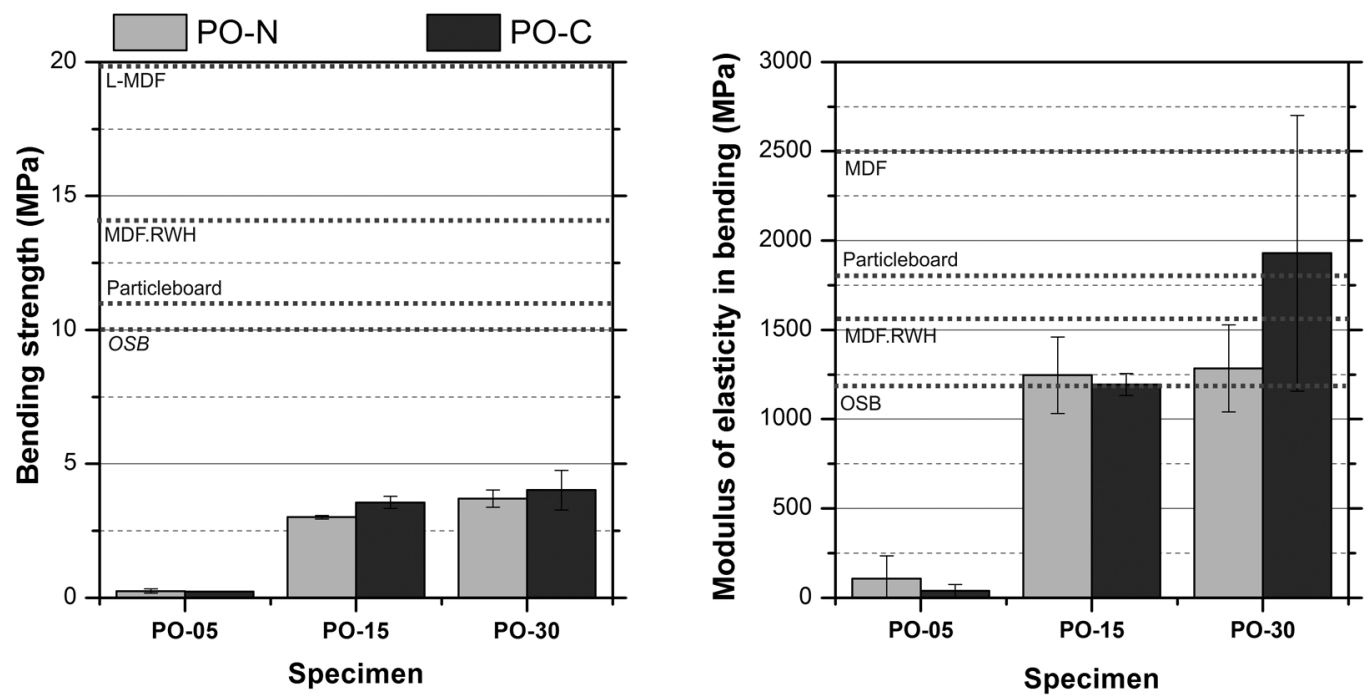

FIGURE 4. Mean bending strength and the mean bending modulus of elasticity for each sample configuration. Minimum required values for typical panels have been included. The vertical error bars represent $+/$ - one standard deviation.

the particleboard and the screw, due to the diminished sizing of the PO in the PO-C boards as compared to the PO-N boards.

Figure 7 shows the mean tensile strength perpendicular to the plane for each of the PO-C y PO-N particleboards tested. The PO-C-05 and PO-N-05 particleboards collapsed upon testing. For this test, increasing the cement in the PO particleboards slightly increases the mean tensile strength perpendicular to the plane. In spite of this, there is still a significant

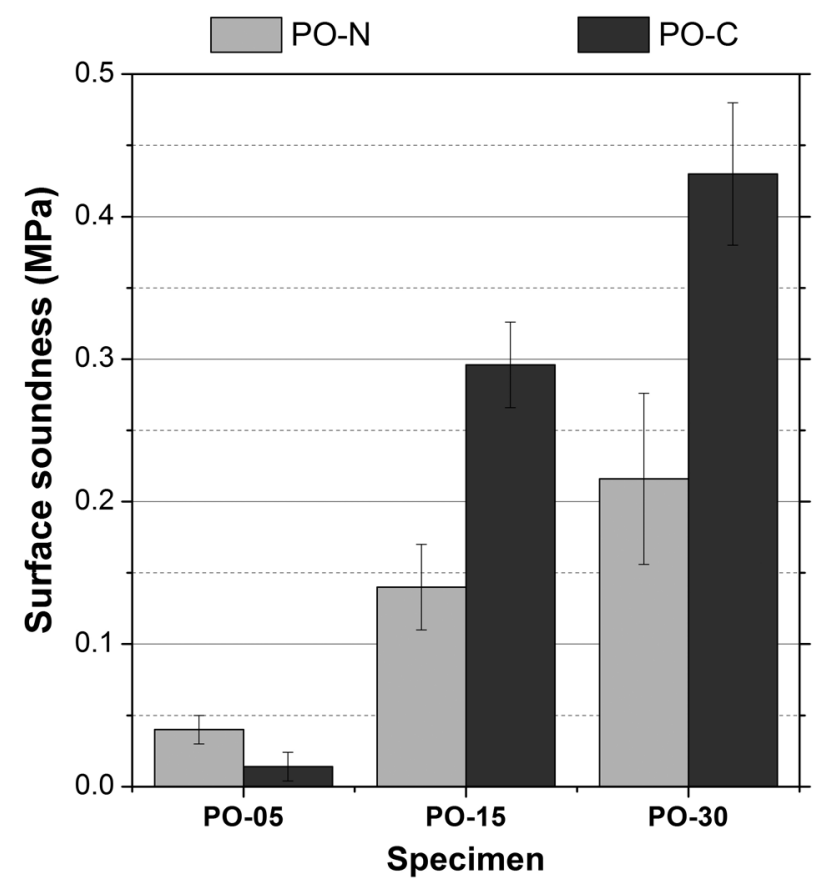

FigURE 5. Mean surface soundness for each sample configuration. influence of leaf morphology on the results. The tensile strengths of the PO-N particleboards were much lower than those of the PO-C particleboards. The PO-N boards were fabricated with leaves in their original state, very much larger than those of the PO-C boards (5 to $1.25 \mathrm{~mm}$ ). In the PO-N board, the leaves are distributed in interconnected layers within the laminar structure of the board, leading to planes of weakness and a resulting lack on tensile strength for this type of board. On the other hand, the PO

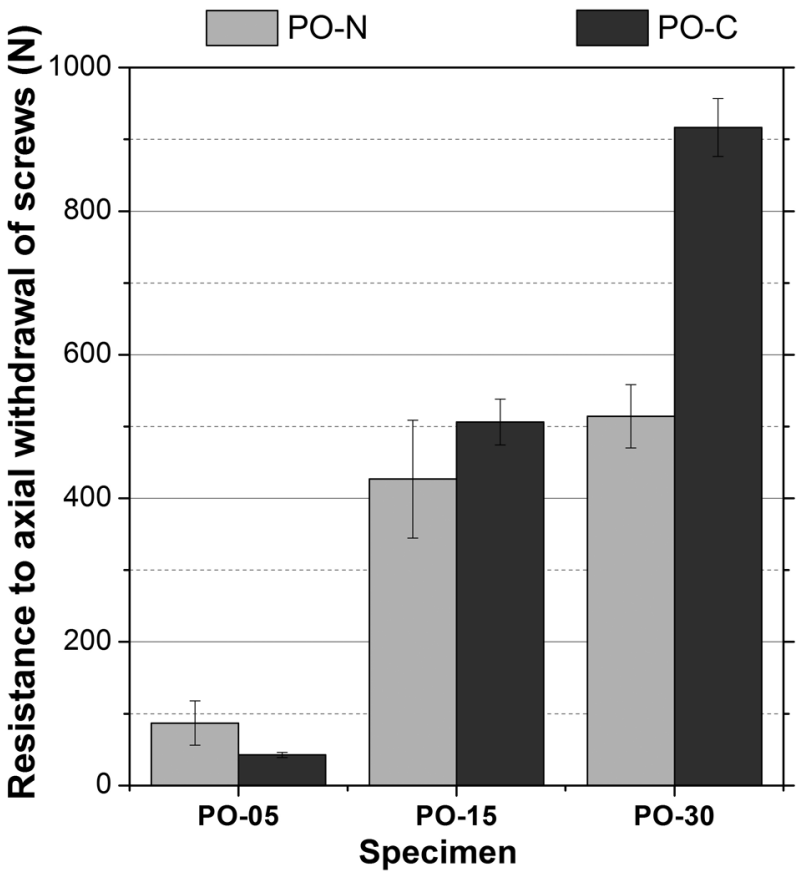

Figure 6. Mean resistance to axial screw withdrawal for each sample configuration. 
distribution in the PO-C boards is a random distribution of small particles leading to a compact structure, without areas of weakness. Additionally, the reduction of the particles' width results in better cohesion at the core of particleboard (24). As may be observed, $\mathrm{PO}-\mathrm{C}-15$ and $\mathrm{PO}-\mathrm{C}-30$ exceed the minimum requirements established for OSB panels.

Figure 8 shows a bar graph of the mean hard body impact resistance for each of the studied board configurations as well as the mean depth of the indentation left by the hard body when penetration occurred. From the data, it may be observed that the resistance to a falling hard body is somewhat independent of both the quantity of cement and the leaf morphology used in PO particleboard fabrication. As expected, the test samples with lesser amounts of cement sustained a larger indentation before sample breakage, from which it may be deduced that the PO produces a damping effect, allowing these samples to better absorb the impact. The PO-N samples, with $\mathrm{PO}$ in its natural state, exhibited a greater damping effect than those with the ground $\mathrm{PO}(\mathrm{PO}-\mathrm{C})$.

\subsection{Porosity}

Figure 9 is a bar graph showing the pore size percentages in terms of the intervals given in section 2.2.1, for each of the PO particleboard configurations. In the particleboards made with modified $\mathrm{PO}$, an evident change exists in the porous structure with increasing cement content. As shown, the

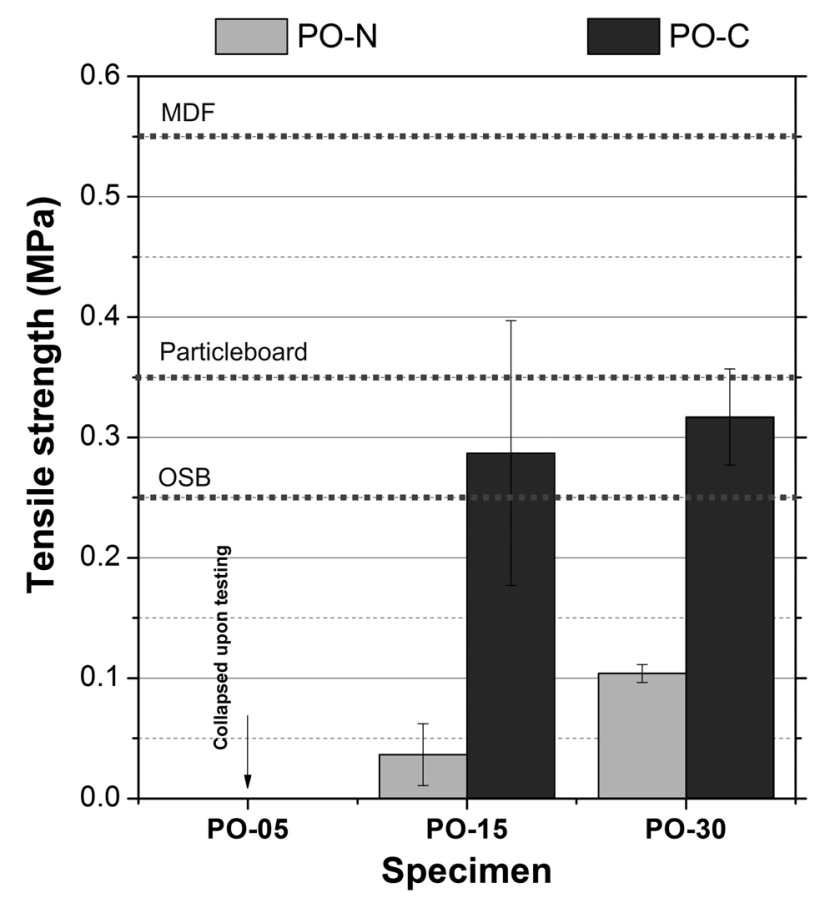

FIGURE 7. Mean Tensile strength perpendicular to the plane of the board for each sample configuration. network of pores becomes finer (a greater proportion of smaller pores) as the quantity of cement in the particleboard increases. It is worth stressing that the increase in small pores (in the interval $<100 \mathrm{~nm}$ ) corresponds to decrease in the largest pores $(>0.1 \mathrm{~mm})$.

Table 8 gives the values of total porosity for each of the PO particleboards based on mercury intrusion porosimetry testing described in section 2.2.1. As shown in Table 8, the value of the total porosity for the test samples decreases with cement content. It is noteworthy that the total porosity for both the PO-C and the PO-N particleboards were similar for the 1.5 and 3 cement mixes, however, for the boards containing the minimum cement (0.5), the PO-C samples had a lower porosity than the PO-N samples.

\subsection{Reaction to fire}

Table 9 gives the epiradiator and single source flame test results along with the calorific values for each of the PO particleboard configurations. From the data it may be seen that the heat of combustion of PO boards is inversely proportional to the cement content. It may also be deduced from Table 9 that the state of the PO (natural or modified) has no influence on the calorific value of the particleboards, since the values for heat of combustion is similar for the two types of board.

In reference to the comments in section 2.2.3, we decided to classify the PO-C and PO-N panels according the Spanish UNE 23727 norm because the final application and sample size are not considered.

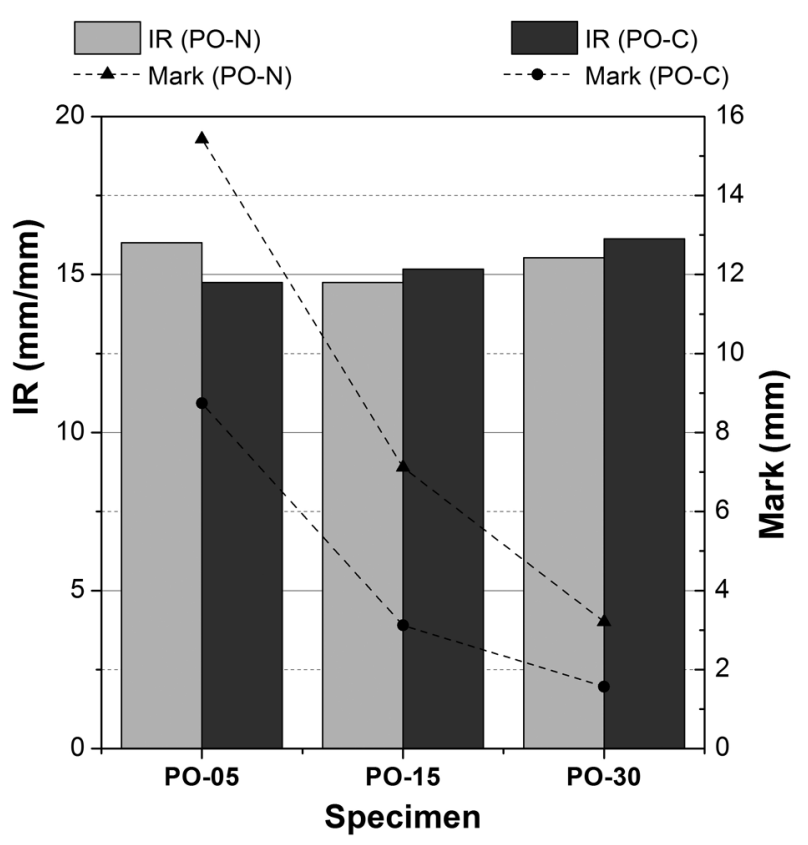

FIGURE 8. Mean hard body impact resistance for each sample configuration. 


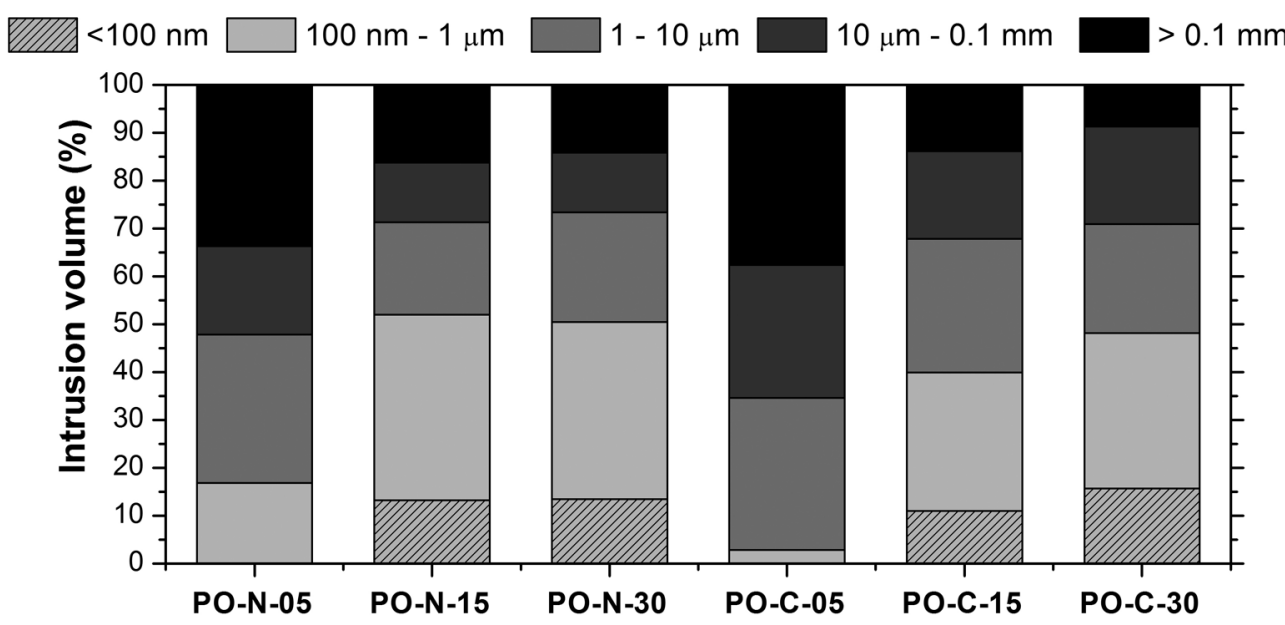

FiguRE 9. Percentage of pore volume for the modified Oceania Posidonia (PO-C) and natural Oceania Posidonia (PO-N) particle boards fabricated with each of the cement quantities.

In addition, the current UNE EN 13501 classification may be estimated using the Table 6 .

Commercial panels are classified as M4, according the out-dated Spanish norm UNE 23727, which means the material is easily flammable. These panels may be made more fire-resistant with flameretardants, which are capable of changing the classification to M1 (non-flammable). The PO-N and PO-C particleboards, independent of the quantity of cement utilized in their fabrication, are classified as M1 materials without any flame-retardant treatments. The particleboards with the least amount of cement experienced a slight emission of white fumes and darkening of the surface after exposure to a torch.
The PO-N particleboards produced an orange flame during the application of an open flame, but combustion stopped when the flame was removed. As such, particleboards are shown to be very fire-resistant.

In the flammability tests for combustion by direct action from a single flame, the surface of the particleboards was exposed to the flame for $30 \mathrm{sec}-$ onds. Neither ignition nor smoke was produced in any of the tests after the flame was removed. The only results were alterations to the surfaces of the samples. There were not any significant differences due to the different mixes composing the samples, except that sample combustion was inversely proportional to the amount of cement content.

TABLE 8. Total porosity of the samples obtained through mercury intrusion porosimetry

\begin{tabular}{|c|c|c|c|c|c|c|}
\hline Specimen & PO-N-05 & PO-N-15 & PO-N-30 & PO-C-05 & PO-C-15 & PO-C-30 \\
\hline Total porosity $(\%)$ & $59.67 \%$ & $58.07 \%$ & $41.65 \%$ & $50.61 \%$ & $58.86 \%$ & $42.23 \%$ \\
\hline
\end{tabular}

TABLE 9. Fire test results

\begin{tabular}{|c|c|c|c|c|c|c|c|c|c|c|c|}
\hline \multirow[b]{3}{*}{ Specimen } & \multirow{3}{*}{$\begin{array}{c}\text { Calorific } \\
\text { value } \\
\text { (MJ/kg) }\end{array}$} & \multicolumn{7}{|c|}{ Radiation test } & \multicolumn{3}{|c|}{ Single-flame source } \\
\hline & & \multicolumn{4}{|c|}{ Index ${ }^{*}$} & \multicolumn{2}{|c|}{ Ignition } & \multirow[b]{2}{*}{ Class $^{* *}$} & \multirow[b]{2}{*}{ Ignitability } & \multirow[b]{2}{*}{ Fumes } & \multirow{2}{*}{$\begin{array}{c}\text { Surface } \\
\text { alteration }\end{array}$} \\
\hline & & i & $\mathbf{s}$ & $\mathbf{h}$ & c & Exposed side & Upper side & & & & \\
\hline PO-C-05 & 8.40 & 0 & 0 & 0 & 0 & 0 & 0 & M1 & No & No & Yes \\
\hline PO-C-15 & 2.76 & 0 & 0 & 0 & 0 & 0 & 0 & M1 & No & No & Yes \\
\hline PO-C-30 & 1.19 & 0 & 0 & 0 & 0 & 0 & 0 & M1 & No & No & Yes \\
\hline PO-N-05 & 8.66 & 0 & 0 & 0 & 0 & 0 & 0 & M1 & No & No & Yes \\
\hline PO-N-15 & 2.91 & 0 & 0 & 0 & 0 & 0 & 0 & M1 & No & No & Yes \\
\hline PO-N-30 & 1.09 & 0 & 0 & 0 & 0 & 0 & 0 & M1 & No & No & Yes \\
\hline
\end{tabular}

${ }_{* *}^{*}$ (Ignitability index), s (spread of flames index), $h$ (flame length) and c (combustion index).

According to UNE 23727. 

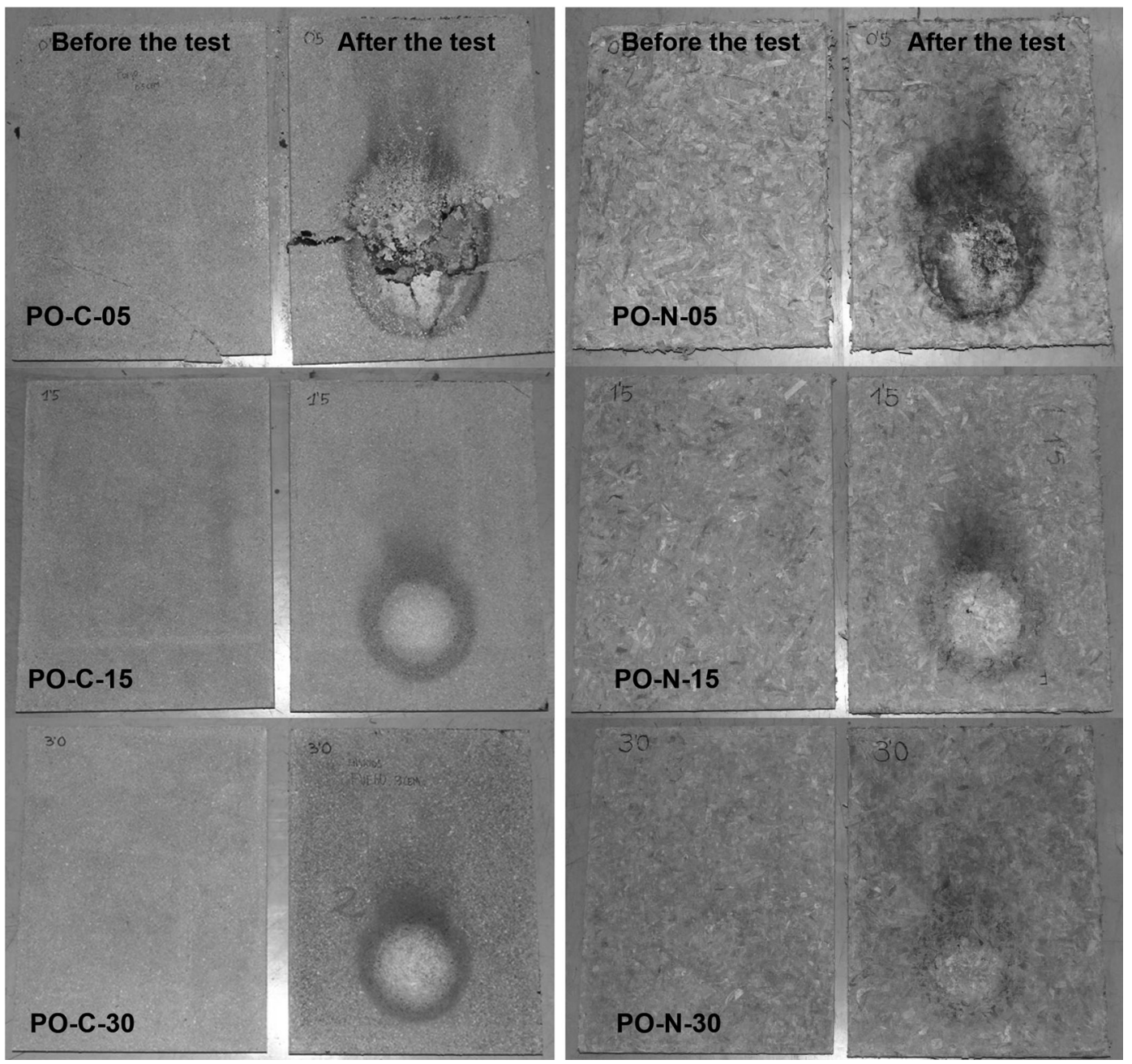

Figure 10. Particle board samples before and after single flame test.

Figure 10 shows the particleboards before and after the single flame tests in which the toxicity analyses were conducted. As may be observed the most affected boards were those with the least cement content. Nevertheless, none of the particleboards caught fire or released smoke during the tests, they were only superficially affected.

\section{CONCLUSIONS}

A large quantity of PO accumulates along the Mediterranean coast causing removal and disposal problems. This study looks at the possibility of combining $\mathrm{PO}$ and cement into a particleboard product. The conclusions of the study are as follows:

The form of the PO that is incorporated into the particleboard has an important influence on the physical and mechanical properties.

- As might be expected, the mechanical and dimensional stability improved considerably by increasing the quantity of cement used during fabrication.

- Particleboards incorporating PO-N showed higher dimensional variation than particleboards made with $\mathrm{PO}-\mathrm{C}$ due to leaf geometry. PO-N waste has less specific surface of PO available. For that reason, these panels have higher cement content per surface unit than PO-C panels. However, PO-C particleboards show lower surface absorption than PO-N particleboards.

- The bending strength and the bending modulus of elasticity were not influenced by the form of PO used in fabrication, but rather by the concentration of cement used in fabrication.

- In the surface soundness, axial screw withdrawal, and tensile strength tests, the form of the PO in the particleboards had a significant influence, with the PO-C particleboards showing better performance in these tests. The PO-N particleboards, manufactured with PO in its natural state, exhibited a laminar structure, while 
the PO-C particleboards have a more compact structure that gives a better cohesion to the particleboard.

- As a result of the flammability tests, the materials were found to be not flammable. There was no flame development at the surface of the particleboards after flame application in testing, only superficial alteration.

\section{ACKNOWLEDGEMENTS}

This study was partially financed by the University of Alicante (GRE10-28) (VIGROB-256) and the Valencian provincial government (GV/2012/113), The authors also wish to express their gratitude to the Instituto Tecnológico de la Construcción (AIDICO) and to the Instituto Tecnológico del Mueble, Madera, Embalajes y Afines (AIDIMA) for its testing support.

\section{BIBLIOGRAPHY}

1. García-Andreu, C.; Saval Pérez, J.M.; Frías Rojas, M.; Chinchón Yepes, S. (2008) Caracterización de las cenizas de Posidonia Oceánica para su utilización como material de construcción, Ingeniería Civil, 149, 131-141.

2. García-Andreu, C.; Saval Pérez, J.M.; Chinchón Yepes, S. (2008) Análisis de las propiedades físicas y mecánicas de morteros de cemento con adición de cenizas de Posidonia Oceánica, Ingeniería Civil, 150, 89-102.

3. Organización de las Naciones Unidas para la agricultura y alimentación. (2011) Situación de los bosques del mundo Roma. http://www.fao.org/docrep/013/i2000s/i2000s00.htm.

4. Guntekin, E.; Uner, B.; Sahin, T.T.; Karakus, B. (2008) Pepper stalks (Capsicum annuum) as a raw material for particleboard manufacturing, Journal of Applied Sciences, 8 [12], 2333-2336. http://dx.doi.org/10.3923/jas.2008.2333.2336.

5. Betkas, I.; Guler, C.; Kalaycioglu, H.; Mengeloglu, F.; Nacar, M. (2005) The Manufacture of Particleboards using Sunflower Stalks (helianthus annuus 1.) And Poplar Wood (populus alba L.), Journal of Composite materials, 35 [5], $467-473$.

6. Guntekin, E.; Karakus, B. (2008) Feasibility of using eggplant (Solanum melongena) stalks in the production of experimental particleboard, Industrial Crops and Products, 27 [3], 354-358. http://dx.doi.org/10.1016/j.indcrop.2007. 12.003 .

7. Yalinkilic, M.K.; Imamura, Y.; Takahashi, M.; Kalaycioglu, H.; Nemli, G.; Demirci, Z.; Ozdemir, T. (1998) Biological, physical and mechanical properties of particleboard manufactured from waste tea leaves. International Biodeterioration \& Biodegradation, 41 [1], 75-84. http:// dx.doi.org/10.1016/S0964-8305(98)80010-3.

8. Nemli, G.; Aydin, A. (2007) Evaluation of the physical and mechanical properties of particleboard made from the needle litter of Pinus pinaster Ait., Industrial Crops and Products, 26 [3], 252-258. http://dx.doi.org/10.1016/j. indcrop.2007.03.016.

9. Nemli, G.; Yildiz, S.; Gezer, E.D. (2008) The potential for using the needle litter of Scotch pine (Pinus sylvestris L.) as a raw material for particleboard manufacturing. Bioresource Technology, 99 [14], 6054-6058. http://dx.doi.org/10.1016/j. biortech.2007.12.044

10. Güler, C; Cöpür, Y; Büyuksan, U, (2009) Producing particleboards from hazelnut (Corylus avellana L.) husk and European Black Pine (Pinus nigra Arnold), Wood Research, 54 [1], 125-132.

11. Nemli, G.; Kirci, H.; Serdar, B.; Ay, N. (2003) Suitability of kiwi (Actinidia sinensis Planch.) prunings for particleboard manufacturing, Industrial Crops and Products, 17 [1], 39-46. http://dx.doi.org/10.1016/S0926-6690(02)00057-2.

12. Nemli, G.; Demirel, S.; Gümüskaya, E.; Aslan, M.; Acar, C. (2009) Feasibility of incorporating waste grass clippings (Lolium perenne L.) in particleboard composites, Waste Management, 29 [3], 1129-1131. http://dx.doi.org/10.1016/j. wasman.2008.07.011

13. Wang, D.; Sun, X. (2002) Low density particleboard from wheat straw and corn pith, Industrial Crops and Products, 15 [1], 43-50. http://dx.doi.org/10.1016/S0926-6690(01)00094-2.

14. Sampathrajan, A.; Vijayaraghavan, N.C.; Swaminathan,K.R. (1992) Mechanical and thermal properties of particle boards made from farm residues, Bioresource Technology, 40 [3], 249-251. http://dx.doi.org/10.1016/0960-8524(92)90151-M.

15. UNE-EN 196-1 (2005) Cemento. Parte 1: Composición, especificaciones y criterios de conformidad de los cementos comunes.

16. UNE 23727 (1990) Ensayos de reacción al fuego de los materiales de construcción. Clasificación de los materiales utilizados en la construcción.

17. UNE EN 13501-1 (2002) Clasificación en función del comportamiento frente al fuego de los productos de construcción y elementos para la edificación. Parte 1: Clasificación a partir de datos obtenidos en ensayos de reacción al fuego.

18. Espinoza-Herrera, R.; Cloutier, A. (2011) Physical and mechanical properties of gypsum particleboard reinforced with Portland cement, European Journal of Wood and Wood Products, 69 [2], 1247-254. http://dx.doi.org/10.1007/ s00107-010-0434-x.

19. Kelly, M. (1997) Critical literature review of relationships between processing parameter and physical properties of particleboard, General Technical Report FPL 10, Madison, 64.

20. Vital, B.; Lehmann, W.; Boone, R. (1974) How species and board densities affect properties of exotic hardwood particleboards, Forest Product Journal, 24 [12], 37-45.

21. UNE-EN 312 (2004) Tableros partículas especificaciones.

22. UNE-EN 622-1 (2004) Tableros fibras. Especificaciones. Parte 1: Requisitos generales.

23. UNE-EN 300 (2007) Tableros de virutas orientadas (OSB). Definiciones, clasificación y especificaciones.

24. González-Prieto, O.; Touza, M.C.; Pereiro, G. (2012) Caracterización de algunas propiedades en tableros de corteza de Pinus pinaster Ait. y tableros de vermiculita expandida, Informes de la Construcción, 64 [526]. 243-251. http:// dx.doi.org/10.3989/ic.10.071. 